\title{
MASS LOSS AND FLAMMABILITY OF INSULATION MATERIALS USED IN SANDWICH PANELS DURING THE PRE-FLASHOVER PHASE OF FIRE
}

\author{
L.L. de Kluiver ${ }^{1}$, A.W. Giunta d'Albani ${ }^{1}$, A.C.J. de Korte $^{1}$, R.A.P. van Herpen ${ }^{1,2}$, R. Weewer ${ }^{3}$ and \\ H.J.H. Brouwers ${ }^{1}$ \\ ${ }^{1}$ Department of the Built Environment, Eindhoven University of Technology, P.O. Box 513, 5600 MB Eindhoven, The \\ Netherlands \\ ${ }^{2}$ Nieman Raadgevende Ingenieurs, P.O. Box 40147, 8004 DC Zwolle, the Netherlands \\ ${ }^{3}$ Instituut Fysieke Veiligheid, P.O. Box 7010, 6801 HA Arnhem, the Netherlands
}

\begin{abstract}
In this study, the mass-loss and flammability limits of different sandwich panels and their cores (PUR, PIR, stone wool, EPS and XPS) are studied separately using a special developed furnace. The focus is on the pre-flashover phase of fire (up to $400^{\circ} \mathrm{C}$ ), because exceeding the lower flammability limit in this phase may lead to a smoke layer explosion, a hazardous situation for an offensive intervention by the fire brigade. The research has shown that the actual mass-loss of synthetic and stone wool based cores is comparable up to $300^{\circ} \mathrm{C}$. From $300^{\circ} \mathrm{C}$ onwards, the massloss of PUR panels is significant. EPS and XPS cores become fluid before pyrolysis starts. Furthermore delamination of the panels can be observed at exposure to temperatures above $250^{\circ} \mathrm{C}$ for the synthetic and $350^{\circ} \mathrm{C}$ for the mineral wool panels. The lower flammability limits have been established experimentally at $39 \% \mathrm{~m} / \mathrm{m}$ (PUR) and $36 \% \mathrm{~m} / \mathrm{m}$ (PS) of the pyrolysis gasses on the air mass, respectively. For PIR and mineral wool no flammability limits could be established.
\end{abstract}

Keywords: flammability limits; mass loss; sandwich panels; insulation material

\section{INTRODUCTION}

Nowadays buildings contain more and more synthetic insulation materials in order to meet the higher demands for energy-performance. These synthetic insulation materials have a different response to fire compared to mineral insulation materials, like stone wool. This study focuses on the pre-flashover phase of fire (up to $400{ }^{\circ} \mathrm{C}$ ), since the fire brigade is still able to intervene inside the fire compartment (offensive fire attack) during this phase.

Besides smoke gas explosions are higher risk during the pre-flashover phase, since the possible presence of the fire brigade inside. Two of the parameters (besides others), which determine the possibility of smoke gas explosions, are the mass loss and flammability of pyrolysis gases. Therefore in this study the mass loss and flammability of pyrolysis gases are experimentally determined. Flammability is both scenario (temperature and fire growth rate) and material dependent (Hull et al. 2007; Crewe et al. 2014). Flammability is measured in this paper for the complete mixture of fire effluents rather than for individual gases, which is usual for chemical analysis. The fire effluent of both synthetic and natural polymers contains a complex mixture of chemicals which will always contain irritating as well as asphyxiating agents (Alarie \& Anderson 1979).

This paper focuses on five different insulation materials, namely stone wool, PUR, PIR, EPS and XPS. These materials can be applied as a core for sandwich panels, as well as single insulation material. From these materials, stone wool is considered as incombustible, while the other materials are in general classified as combustible. 


\section{EXPERIMENTAL SETUP}

\subsection{Setup}

Two different series of experiments were performed in this study, a) the mass-loss and b) the flammability experiment. Both experiments use the same basic furnace with some further specified modification. The basic furnace (Figure 1) has an inner space of $30 \mathrm{~cm} \cdot 30 \mathrm{~cm} \cdot 60 \mathrm{~cm}(1 \cdot \mathrm{w} \cdot \mathrm{h})$ and is built with autoclaved aerated gas concrete (AAC) blocks. These blocks were covered with aluminium foil, to decrease the absorption of pyrolysis gases by the gas concrete blocks and to create an acceptable air tightness. The heating of the furnace is done by a large electric heating element of 2300 Watt with a dimension of $20 \cdot 30 \mathrm{~cm}$. The samples will be equally exposed to the radiation due to the size of the heating element. The heating element is connected to a sheetthermocouple that has been placed at the front side of the furnace, just below the surface of the frame in which the sample is placed. This position allows determining the temperature at the height of the sample without blocking a part of the sample. The heat element is controlled by this sheet thermocouple which is attached to the self-adjusting temperature controller type West 6100 .

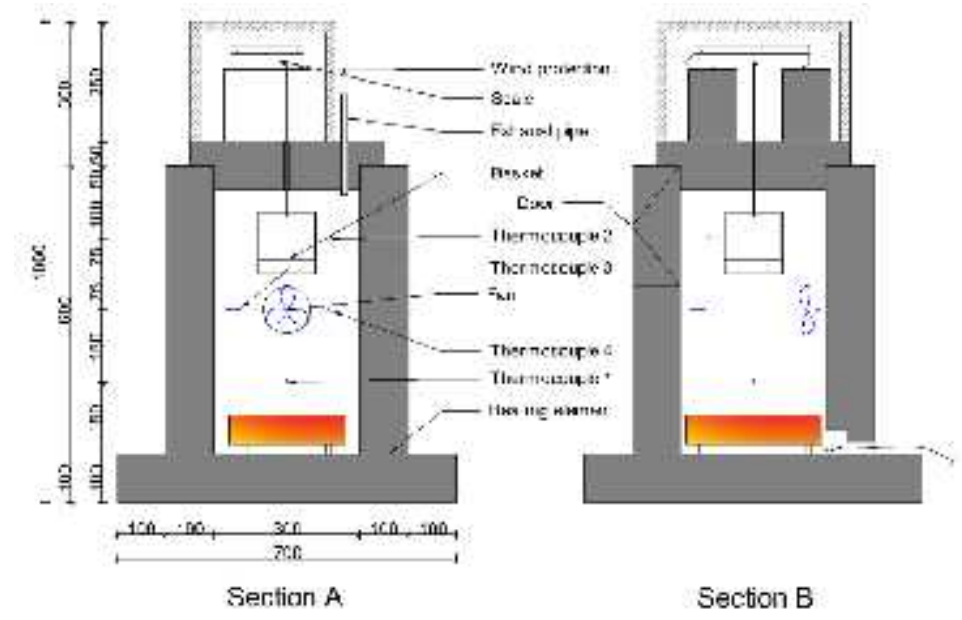

Fig. 1 Drawing of the basic furnace with K1, K2, K4 as the fitted thermocouples, 1 the location of the sample in case of the mass loss experiments and 2 the heating element of $1750 \mathrm{~W}$.

The heating of the samples is done by an electronic heating element, in order to minimize the influence on the composition of gases by possible unburnt fuels. Gas burners would influence the composition of fire effluent.

During the mass loss experiment 3 different constant temperatures are used (150, 250 and $\left.350{ }^{\circ} \mathrm{C}\right)$. $150{ }^{\circ} \mathrm{C}$ has been chosen as lower limit since degradation of the adhesive layers starts at around 150 ${ }^{\circ} \mathrm{C}$, the upper limit has been set at $350{ }^{\circ} \mathrm{C}$. This temperature corresponds to the temperature to which a fire fighter can be safely exposed. This corresponds to radiation flux of $4.5 \mathrm{~kW} / \mathrm{m}^{2}$ for a duration of 20 minutes with a view factor of 0.5 . This radiation flux is given by AFAC (Robbins \& Wade 2008).

The sample is placed in a sample tray. This sample tray has dimensions $29.8 \cdot 29.8 \mathrm{~cm}$ made out of L-steel profile $50 \cdot 50 \cdot 5 \mathrm{~mm}$ and a self-weight of $4.133 \mathrm{~kg}$ and is supported by steel L profiles, which are mounted to the sides of the furnace. The samples are insulated with ceramic insulation to prevent heat transfer through the sides of the sample. In order to create a realistic situation for the mass-loss experiment, the top part of the furnace needs to be open, so the "outside" of the sample is exposed to ambient temperatures while being exposed to heat within the furnace.

Unlike the mass-loss experiment, the experimental setup for flammability experiment was closed using a lid. Furthermore the sample is placed in a bucket in the middle of the furnace and its mass is measured continuously by a scale on top of the furnace. Besides that, the flammability experiment uses an increasing temperature from ambient till $400^{\circ} \mathrm{C}$, while for the mass loss experiment three fixed temperatures are applied during the experiment. 
The flammability itself is tested outside the furnace by using an exhaust pipe. Three different ways to ignite the gasses were applied, namely piezoelectric element, regular lighter and glass bottle with lighter. The glass bottle method uses a glass bottle to capture the gas mixture from the exhaust and the gas mixture is than ignited with regular lighter. The flammability limit is the mass-based ratio of mass of the pyrolysis gases on total mass of gases (the air flow) present.

\subsection{Materials}

The tested materials are PUR, PIR, EPS, XPS and stone wool. PUR, PIR and stone wool are tested both on the core materials (flammability experiment) as well as sandwich panel samples (mass loss experiment). Experiments on EPS and XPS were only done on the core materials, since due to the melting testing the panels of these materials was not possible. The properties of the tested samples are shown in Table 1.

Table 1 Physical properties of the different insulation materials used in this research (Fire safety class according to Eurocode (2000))

\begin{tabular}{|l|c|c|c|c|}
\hline & PUR & PIR & Stone wool roof & Stone wool wall \\
\hline Density $\left(\mathrm{kg} / \mathrm{m}^{3}\right)$ & 30 & 50 & 100 & 100 \\
\hline Conductivity $(\mathrm{W} /(\mathrm{m} \mathrm{K}))$ & 0.023 & 0.023 & 0.041 & 0.042 \\
\hline Thickness $(\mathrm{mm})$ & $100 / 135$ & $80 / 115$ & $60 / 100$ & 100 \\
\hline $\mathrm{R}_{\mathrm{c}}$-value $\left(\mathrm{m}^{2} \mathrm{~K} / \mathrm{W}\right)$ & 4.92 & 4.59 & & 19.1 \\
\hline Weight $\left(\mathrm{kg} / \mathrm{m}^{2}\right)$ & 12.9 & 11.6 & 17.7 & $\mathrm{~A} 1$ \\
\hline Fire safety class & B-s2,d0 & $\begin{array}{c}\text { B-s2,d0 } \\
\text { B-s1,d0 }\end{array}$ & A1 & \\
\hline
\end{tabular}

The samples as tested during the mass loss experiment are $25 \cdot 25 \mathrm{~cm}$ of which an area of $20 \cdot 20$ has been exposed to the heat source, sandwich panel samples come in 2 different types, namely samples with joints (in the length direction) and samples without joints.

The tested samples during the flammability experiment were $10 \cdot 10 \mathrm{~cm}$ and height of the samples was equal to the height of the core material within the sandwich panel. These samples are tested without the metal facing of the sandwich panels.

\section{EXPERIMENTAL RESULTS}

\subsection{Experiments on core material samples}

Table 2 shows the mass losses found during the flammability experiments. As one can notice from these mass losses, the temperature to which the sample is exposed is of large influence on the mass loss of the sample. While at $250{ }^{\circ} \mathrm{C}$ the mass losses are in the range up to $2 \%$, at $400{ }^{\circ} \mathrm{C}$ the synthetic insulation materials experience larger mass losses. PIR experiences a mass loss of $28 \%$ at $400^{\circ} \mathrm{C}$, PUR has a mass loss $44 \%$, and both polystyrene based materials (EPS and XPS) have a mass loss of $87 \%$, while the stone wool experiences only a mass loss of $4 \% \mathrm{~m} / \mathrm{m}$.

From literature, thermogravimetric analysis (TGA) of PIR and PUR are available. These TGA's can be compared to the mass-loss determined during the flammability experiment. Figure 2 shows the TGAs and mass losses of PIR and PUR, respectively. The mass loss here is slower than the TGA, which can be explained by thermal inertia/slowness of the sample due to the sample size. The sample size of a TGA is few milligram of material, while the sample size in this experiment is around 20 grams of material. In the case of the latter, it takes more time for the heat to the sample. Table 3 shows the derived flammability limits during the experiments. The flammability limits for PIR and stone wool could not be found during the current experiments. For PUR a lower 
flammability limit (LFL) of $39 \% \mathrm{~m} / \mathrm{m}$ and a upper flammability limit (UFL) of $78 \% \mathrm{~m} / \mathrm{m}$ were found. For the polystyrene materials (EPS and XPS) only the lower limit could be derived, being around $36 \%$ for both these materials. During the current experiments, no upper limit could be established for these polystyrene materials.

Table 2 The mass loss (in mass percentage) which occurred during the flammability tests.

\begin{tabular}{|l|c|c|}
\hline Materials & $250{ }^{\circ} \mathrm{C}$ & $400{ }^{\circ} \mathrm{C}$ \\
\hline PUR & $1.8 \%$ & $44 \%$ \\
\hline PIR & $1.8 \%$ & $28 \%$ \\
\hline Stone Wool Core & $0.2 \%$ & $4 \%$ \\
\hline Stone Wool Panel & $0.7 \%$ & $9 \%$ \\
\hline Polystyrene & $1.9 \%$ & $87 \%$ \\
\hline
\end{tabular}

Table 3 The measured ranges and derived flammability ranges (in $\% \mathrm{~m} / \mathrm{m}$ ) during flammability tests.

\begin{tabular}{|l|c|c|c|}
\hline & Test range & LFL & UFL \\
\hline PUR & $12-89 \%$ & $39 \%$ & $78 \%$ \\
\hline PIR & $14-84 \%$ & - & - \\
\hline Stone wool & $2-55 \%$ & - & - \\
\hline Polystyrene & & $36 \%$ & $>95 \%$ \\
\hline
\end{tabular}

In literature, the lower flammability limit given for styrene gases is $1.1 \% \mathrm{~V} / \mathrm{V}$ (Yaws 2001). Assuming that the gases produced during the current experiments are fully polystyrene, the volumebased lower flammability range can be calculated and would be $16 \% \mathrm{~V} / \mathrm{V}$. This is ten times the value given by Yaws (2001). The difference can be explained since the pyrolysis product is probably not (mono) styrene gas, but contains longer chains of styrene molecules, which are more difficult to ignite. Furthermore, the temperature during the flammability experiment is low compared to the experiments in literature, causing more difficult ignition.
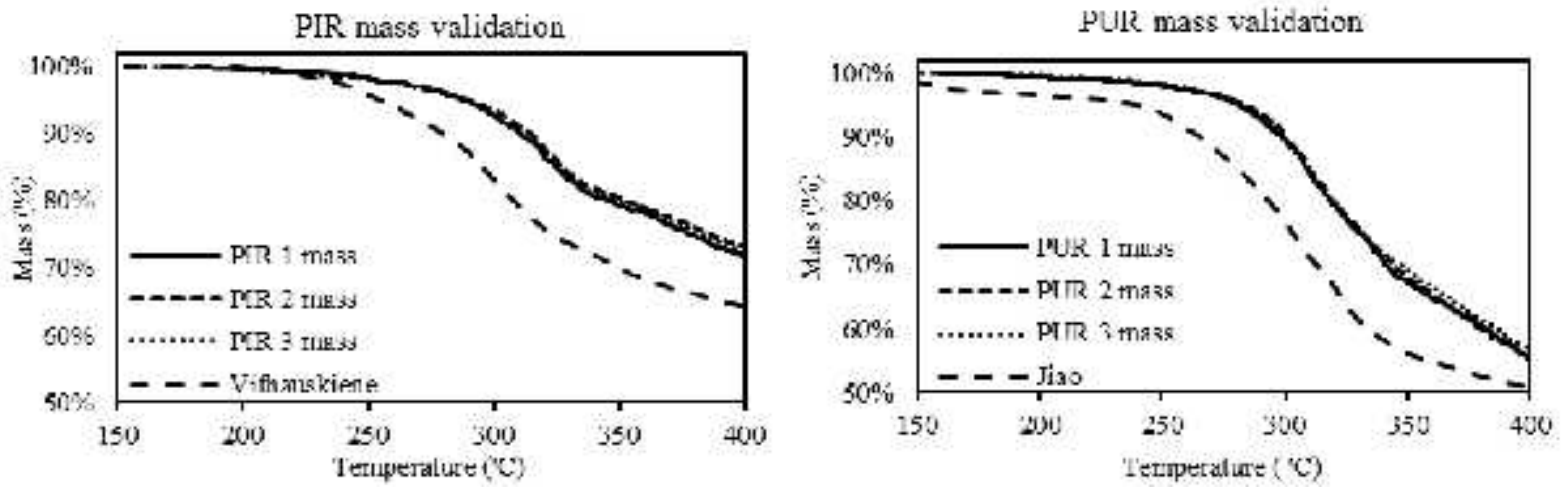

Fig. 2 The mass loss of PIR and PUR during the flammability experiment and the mass loss in the TGA measurement of Vithauskiene et al. and Jiao et al. (Vithauskiene et al. 2011; Jiao et al. 2013)

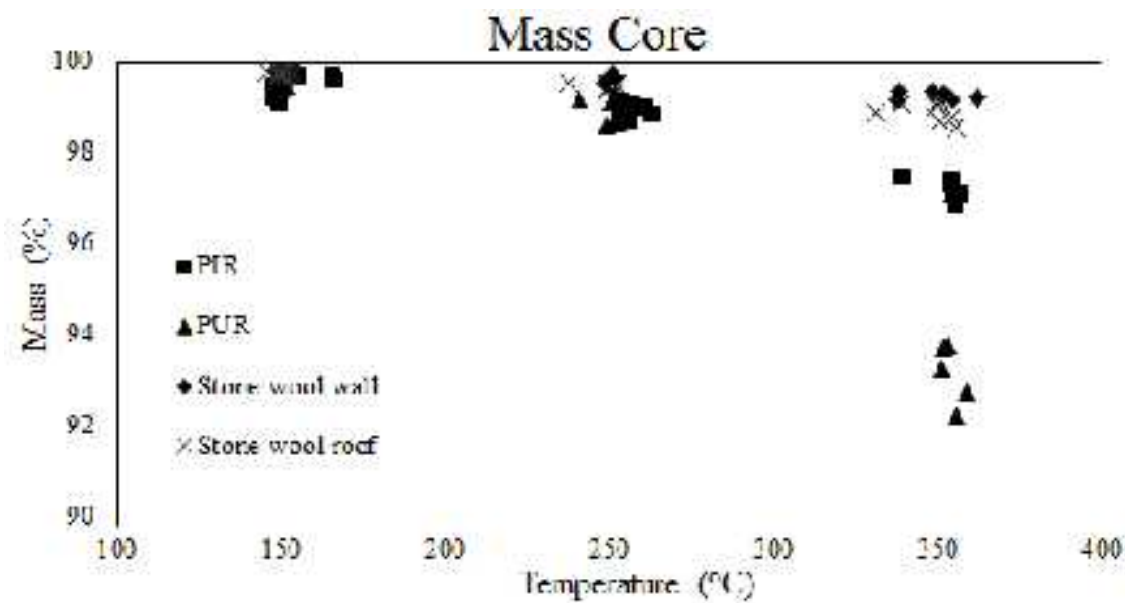

Fig. 3 The total mass of the core, after the mass-loss experiments at different temperatures. 


\subsection{Experiments on sandwich elements}

The mass loss has been measured, resulting in the number as shown in Table 4 and Figure 3 . The mass-loss of mineral wool panels shows a linear trend, while the mass loss of PIR panels slightly increases as the temperature rises. PUR panels show a different pattern, the mass loss increases rapidly when the temperature of $300{ }^{\circ} \mathrm{C}$ is exceeded. This process is expected to be continuous until the material is completely pyrolysed. This leads to the assumption that the significant mass loss starts at the upper limit of this research $\left(400{ }^{\circ} \mathrm{C}\right)$.

Due to the heat exposure of the sample to one side, the heat has to migrate through the sample, and there will be a temperature gradient across the sample. This influences the mass loss. This causes a pattern that is similar for all the different materials. The temperature at a height of $3 \mathrm{~cm}$ is measured during the mass loss experiments using a thermocouple (K3). The average intrusion depth varies between 1.52 and $1.69 \mathrm{~cm}$ (Table 4). If this area is taken as the influenced area, the mass loss percentage of the material can be determined. The weight of the steel facings is not included in the calculations.

Table 4 The mass loss (in gram) and the intrusion depth of the degradation front and mass loss percentage at $350{ }^{\circ} \mathrm{C}$ during the mass loss test.

\begin{tabular}{|ll|c|c|c|c|}
\hline \multicolumn{2}{|l|}{ Core type } & PIR & PUR & Stone wool wall & Stone wool roof \\
\hline \multirow{2}{*}{ Mass loss $(\mathrm{g})$} & $\begin{array}{l}150^{\circ} \mathrm{C} \\
250^{\circ} \mathrm{C}\end{array}$ & 1.72 & 1.05 & 1.17 & 1.78 \\
\cline { 4 - 6 } & $350^{\circ} \mathrm{C}$ & 8.92 & 15.12 & 5.22 & 2.45 \\
\cline { 3 - 6 } & & 1.61 & 1.52 & 1.69 & 4.63 \\
\hline Intrusion depth $(\mathrm{cm})$ & 30.97 & 18.31 & 66.83 & 1.65 \\
\hline Core mass & 8.92 & 15.12 & 4.63 & 5.45 \\
\hline Mass loss & 29.0 & 83.0 & 7.0 & 7.0 \\
\hline Mass loss \% of core & & &
\end{tabular}

The stone wool samples lost approximately $7 \%$ of their mass, of which a significant (3\% assumed) part can be assigned to the adhesive layer that binds the facing to the core material. The material shows discolorations at high temperatures and loses strength. PIR panel lost $29 \%$ mass of the core, the tested samples contain an adhesive layer. Samples exposed to temperatures larger than $250{ }^{\circ} \mathrm{C}$, expand due to the formation of a honeycomb structure a larger open cell structure). This honeycomb structure protects the remainder of the core material. The PUR samples show a mass loss of $83 \%$ due to the pyrolysis that occurs in the influenced area, at high temperatures. The exposed PUR melts and quickly turns into pyrolysis gas.

The mass loss of the influenced area is significantly higher that the mass loss percentages of the complete samples, which give $0.4 \%$ mass loss for stone wool samples, $1.0 \%$ mass loss for PIR samples and $1.6 \%$ mass loss for PUR samples.

\subsection{Visible observations}

All materials resist temperatures up to $150{ }^{\circ} \mathrm{C}$ without significant damage or mass loss, the mass loss ranges between 0.9 grams and 2.0 grams. All materials show no reaction to the heat exposure, except stone wool wall panels, which produce a slight odour while testing. At a temperature of 250 ${ }^{\circ} \mathrm{C}$ there is a slight difference between the stone wool panels and the foam panels, the foam panels show small signs of delamination combined with an increasing mass loss of 3.0 up to 3.3 grams. After removing the inner steel facing the core materials show discoloured foam, both foams show larger cells within their foam. Whereas the stone wool panels do not show any signs of delamination and a mass loss of 2.4 - 2.6 grams after removing the inner steel facing the adhesive layer shows discoloration. At temperatures of $350{ }^{\circ} \mathrm{C}$ all panels delaminate, and produce smoke, 
stone wool panels produce a strong odour of burned glue, the PIR panels form a honeycomb structure, the PUR panel cores pyrolyse, the stone wool cores show discoloration of the core materials.

\section{CONCLUSIONS}

For this research, a special furnace has been designed and build, which has the capability to oneside exposure of sandwich panels and their core materials (stone wool, PUR, PIR, EPS, XPS). Using this special furnace, the effect of realistic fire scenario/conditions is investigated. The research shows that delamination can occur due to degradation of the resin between metal facings and the core. In case of PUR, delamination can also occur due to the gasification of the core material.

A mass loss of $7 \%, 29 \%$ and $83 \%$ has occurred at temperatures of $350{ }^{\circ} \mathrm{C}$ for stone wool, PIR and PUR sandwich panels, respectively. The mass loss of PUR was slowly linearly increasing for temperatures up to $300{ }^{\circ} \mathrm{C}$, but a rapid mass loss occurs from this temperature onwards, due to gasification of the PUR core.

Furthermore, the progress of the degradation front at different temperature was clearly visible when the sandwich panels were cut in two parts. Another visible change to the material is the formation of char and the foaming of the core.

The flammability ranges for the different insulations core were determined experimentally. The lower and upper flammability ranges for PUR are 39 and $78 \% \mathrm{~m} / \mathrm{m}$, respectively. A lower flammability for EPS and XPS of $36 \% \mathrm{~m} / \mathrm{m}$ was found, but during the experiments the upper limit was not found. The effluent of the heating of stone wool and PIR cores could not be ignited during the experiments.

\section{Acknowledgements}

The authors wish to express their sincere thanks to Brandweer Nederland (dr. Ricardo Weewer), Fellowship FSE WO2 foundation (ir. Ruud van Herpen), Kingspan, Rockwool, Stybenex for their technical support and advises. They furthermore thank the sponsors of the user/sponsor group Cement-Immobilisates-Concrete. Furthermore the authors wish to thank the experts from the field, Roy Weghorst, Benedikt van Roosmaalen, Peter van de Leur and Jacques Mertens, for their input.

\section{References}

Alarie, Y.C. \& Anderson, R.C., 1979. Toxicologic and acute lethal hazard evaluation of thermal decomposition products of synthetic and natural polymers. Toxicology and Applied Pharmacology, 51(2), pp.341-362.

Crewe, R.J. et al., 2014. Experimental Results of a Residential House Fire Test on Tenability: Temperature, Smoke, and Gas Analyses. Journal of Forensic Sciences, 59(1), pp.139-154.

Eurocode, 2000. Implementing Council Directive 89/106/EEC as regards the classification on the reaction to fire performance of construction products.

Hull, T.R. et al., 2007. Factors affecting the combustion toxicity of polymeric materials. Polymer Degradation and Stability, 92(12), pp.2239-2246.

Jiao, L. et al., 2013. Thermal degradation characteristics of rigid polyurethane foam and the volatile products analysis with TG-FTIR-MS. Polymer Degradation and Stability, 98(12), pp.2687-2696.

Robbins, A.P. \& Wade, C.A., 2008. Effective passive roof venting in the event of a fire; Part 1: Preliminary Modelling Results, BRANZ.

Vitkauskien, I. et al., 2011. Thermal Properties of Polyurethane-Polyisocyanurate Foams Based on Poly(ethylene terephthalate) Waste. Materials Science, 17(3). Available at: http://www.matsc.ktu.lt/index.php/MatSc/article/view/588 [Accessed November 13, 2014].

Yaws, C.L., 2001. Matheson gas data book 7th ed., Parsippany, NJ : New York: Matheson Tri-Gas; McGraw-Hill. 